\title{
Agresif periodontitis hastalarında periodontal doku yıkımının dişeti oluğu sıvısı hacmi üzerine etkisi
}

\author{
Şadiye Coşkuner ${ }^{1}$, Nilgün Özlem Alptekin ${ }^{2}$
}

Selcuk Dent J, 2016; 3: 98-106

Başvuru Tarihi: 13 Nisan 2016 Yayına Kabul Tarihi: 03 Kasım 2016

\begin{abstract}
öz
Agresif periodontitis hastalarında periodontal doku yıkımının dişeti oluğu sıvısı hacmi üzerine etkisi

Amaç: Bu çalışmada agresif periodontitis (AP) hastalarının dişet oluğu sIVISI (DOS) hacim değerlerinin belirlenmesi ve periodontal yıkım derecesinin DOS hacmi üzerine olan etkisinin değerlendirilmesi amaçlandı.
\end{abstract}

Gereç ve Yöntemler: Bu kesitsel çalışma Selçuk Üniversitesi, Diş hekimliği Fakültesi, Periodontoloji bölümünde yürütüldü. Araştırmaya $80 \mathrm{AP}$ ve yas ve cinsiyet olarak eşleştirilmiş 80 periodontal olarak sağlıklı (S) olmak üzere toplam 160 birey dahi edildi. Hastalardan klinik olarak plak indeksi (PI), gingival indeks (Gi), sondlama cep derinliği (SCD) ve klinik atașman kaybı (KAK) değerleri kaydedildi. Çalışmaya dahil edilen 50 lokalize (L) AP, 30 generalize (G) AP ve $80 \mathrm{~S}$ olmak üzere toplam 160 bireyden DOS alındı. Elde edilen DOS hacim değerleri elektronik hacim ölçücü Periotron ile değerlendirildi (Periotron 8000, OroFlow Inc.)

Bulgular: $S$ kontrollerle kıyaslandığında tüm klinik parametreler LAP ve GAP hastalarında anlamlı derecede yüksekti $(p<0.05)$ DOS hacim değerleri AP hastalarında anlamlı derecede yüksek olmasına rağmen $(p<0.05)$, LAP ve GAP hastaları arasındaki farklılık istatistiksel olarak anlamlı bulunmadı $(p>0.05)$.

Sonuç: DOS hacim değerleri örneklemenin yapılmasından analiz edilinceye kadarki süreçte birçok faktör tarafından etkilenebilir. Bu nedenle araştırmacıların DOS hacim değerlerinin belirlenmesinde çok dikkatli olmaları gerekmektedir. Bu araștırmanın sınırları dahilinde periodontal yıkım derecesinin DOS hacim değerlerin etkilemediği sonucuna varılabilir.

\section{ANAHTAR KELIMELER}

Agresif periodontitis, dişeti oluğu sıvısı, periodontal hastalık

Agresif periodontitis (AP), ergen ve genç erişkin dönemindeki sistemik olarak sağlıkı bireyleri etkileyen periodontal dokuların hızlı kaybı ile karakterize bir hastalıktır ve periodontal hastalıkların heterojen bir grubunu oluşturur (Armitage 1999). Genel popülasyonda az bir oranda görülmesine rağmen (\%0.1-5) (Albandar ve Tinoco 2002), hastalı̆ı̆ı etiyoloji ve patogenezinin anlaşımasını amaçlayan çalışmalar üzerine büyük ilgi duyulmaktadır.

\section{ABSTRACT \\ The effect of periodontal destruction on gingival crevicular fluid volume in patients with aggressive periodontitis}

Background: The present study aimed to determine the gingival crevicular fluid (GCF) volume of Aggressive periodontitis patients and to detect whether the degree of destruction effects the volume of GCF.

Methods: This cross-sectional study was carried out at Selcuk University, Faculty of Dentistry, Department of Periodontology. A total of 160 subjects including, 80 Aggressive periodontitis (AP) and 80 age and gender matched periodontally healthy $(H)$ controls were recruited. Clinical periodontal measurements including plaque index (PI), gingival index (GI), proping depth (PD) and clinical attachment loss (CAL) were performed. GCF samples were collected from 160 patients including 50 localized (L) AP, 30 generalized (G) AP and $80 \mathrm{H}$. Volume of GCF samples were measured by an electronic device (Periotron 8000 , OroFlow Inc.).

Results: Compared to $\mathrm{H}$ controls, all clinical parameters were significantly higher in subjects with LAP and GAP $(p<0.05)$. Although volume of GCF was significantly higher in AP patients $(p<0.05)$, there were no differences between LAP and GAP $(p>0.05)$.

Conclusion: GCF volume can be affected by several factors from sampling to analysing. For this reason researchers have to be careful in determining the volume measurements of GCF. In the limit of this study we may speculate that the degree of periodontal destruction may not effect the GCF volume in patients with GAP.

\section{KEYWORDS}

Aggressive periodontitis, gingival crevicular fluid, periodontal disease

Birçok sistemik hastalığın tanımlanmasında biyolojik sıvıların ve dokuların laboratuvar analizleri kullanılmaktadır (Lamster ve Novak 1992). Periodontoloji alanında yapılan çalışmalar ise hastalık sürecinin anlaşılması ve aynı zamanda mevcut klinik limitasyonların üstesinden gelinmesi için güvenilir, teşhise yönelik testlerin geliştirilmesi amacıyla Dişeti oluğu sıvısı (DOS) analizi üzerinde durmaktadır

\footnotetext{
${ }^{1}$ Abant İzzet Baysal Üniversitesi Diş Hekimliği Fakültesi Periodontoloji Anabilim Dalı, Bolu

2 Başkent Üniversitesi Diş Hekimliği Fakültesi Periodontoloji Anabilim Dalı, Ankara
} 
(Kleinberg ve Golub 1985, Persson ve ark. 1990, Johnson 1991, Page 1992). Bu amaçla periodontal hastalıkta savunma sistemi bileşenlerinin (Anil ve ark. 2013), doku yıkım ürünlerinin (Leppilahti ve ark. 2014), akut faz proteinlerinin (Becerik ve ark. 2012), enflamatuvar belirteçlerin (Kurtis ve ark. 2005), sitokinlerin (Sakai ve ark. 2006) ve enzimlerin (Hernandez ve ark. 2010) birçoğu DOS'da analiz edilmiştir.

Dişeti oluğu sıvısının toplanması amacıyla kapiller tüp (Pradeep ve ark. 2009), gingival yıkama (Guentsch ve ark. 2011) ve kağıt şerit/koni (Ustun ve Alptekin 2007) gibi farklı yöntemler kullanılmaktadır. Bölgesel olarak kolay ve hızlı uygulanabilmesi ve dişetinde oluşturduğu travmanın en az olması gibi avantajlarından dolayı kağıt şerit yöntemi sıklıkla tercih edilmektedir. DOS örneklerinin kağıt şerit ile toplanmasında sulkus dışı "extracrevicular" ve sulkus içi "intracrevicular" olmak üzere iki yöntem kullanılmaktadır. Sulkus içi yöntem sıklıkla kullanılmakla birlikte kağıt şerit sulkus içine yerleştirildiği için, sulkus dışı yönteme göre daha hassas olmakta (Loe ve Holm-Pedersen 1965, Griffiths 2003) ve kağıt şeridin sulkus/periodontal cep içerisine yerleştirilme derinliğine göre de alt gruplara ayrılmaktadır. Bunlar modifiye sulkus içi "modified intracrevicular" yöntem (Loe ve Holm-Pedersen 1965, Nowicki ve ark. 1981, Stoller ve ark. 1990) ve periodontal cep tabanında direç hissedilinceye kadar ilerletilmesi olan derin sulkus içi "deep intracrevicular" (Griffiths 2003) yöntem olmaktadır. Derin sulkus içi yöntem, gingival sulkusta doku hasarına neden olabilmekte ve buna bağlı DOS akış hızı değişmektedir ve periodontal cep derinlikleri farklı olabileceği için standardizasyonun sağlanması zor olmaktadır (Mann 1963).

Günümüze kadar yapılan çalışmalarda DOS'un hacimsel değişimlerin hastalığın erken dönemlerinde önemli bir teşhis parametresi olabileceği bildirilmektedir (Griffiths 2003). Bununla birlikte sigara kullanımı (Ustun ve Alptekin 2007), seks hormonları (Markou ve ark. 2009), mekanik uyarı (Griffiths 2003), kullanılan ilaçlar (Ho ve ark. 2010) ve sirkadyen periyod (Bergmann ve Deinzer 2008) gibi birçok faktörün DOS hacmini etkileyebileceği gösterilmiştir. Dişeti oluğu sıvısının hacimsel değerleri, özellikle DOS temelli çalışmalarının konsantrasyon hesaplamalarında çok önemli olmakta ve çalışmaların sonuçlarının doğru bir şekilde yorumlanmasında güvenilirliği önemli derecede etkileyebilmektedir.

Literatürde toplanan DOS hacminin sadece periodontal dokulardaki enflamasyon derecesi ile paralel olarak artış göstermediği aynı zamanda sulkuler/cep epitelinin ülserasyon derecesinin de DOS hacmini etkilediği rapor edilmiştir (Armitage 2004). Bu nedenle bu çalışmada I) AP hastalarının DOS hacimlerinin belirlenmesi ve $S$ kontrollerle kıyaslanması ve II) DOS hacminin periodontal yıkım derecesine göre Lokalize AP (LAP) ve Generalize AP (GAP) teşhisi konulmuş bireyler arasında farklı olup olmadığının değerlendirilmesi amaçlanmıştır.

\section{GEREÇ VE YÖNTEM}

$\mathrm{Bu}$ çalışma Selçuk Üniversitesi Diş Hekimliği Fakültesi'ne Mart 2011 ile Ağustos 2012 tarihleri arasında gelen, klinik ve radyografik olarak Agresif periodontitis (Armitage 1999) teşhisi konulan 80 hasta (50 LAP, 30 GAP) ve periodontal olarak sağlıklı 80 gönüllü olmak üzere toplam 160 birey üzerinde yürütüldü. Son altı ay içerisinde antibiyotik kullanan ve periodontal olarak tedavi gören, kardiyovasküler rahatsızlığı, metabolik hastalığı olan, insan immun yetmezlik virüsü "Human immunodeficiency virus" (HIV) ile enfekte, Hepatit A, B veya C virüsü taşıyan, ağız içerisinde $<16$ daimi dişi olan ve ortodontik olarak tedavi edilmiş ve sigara kullanan bireyler araştırmaya dahil edilmedi. Araştırma için Selçuk Üniversitesi Meram Tıp Fakültesi Etik Kurulu'ndan onay alındı (Karar sayısı 2011/016). Çalışmaya dahil edilen tüm bireylere araştırmanın amacı ve içeriği detaylı olarak anlatılıktan ve aydınlatımış onam formları imzalandıktan sonra araştırmaya başlandı.

\section{Klinik periodontal değerlendirme}

Klinik olarak plak indeksi (Pi) (Silness ve Loe 1964), gingival indeks (Gi) (Loe ve Silness 1963), sondlama cep derinliği (SCD) ve klinik ataşman kaybı (KAK) ölçümleri yapıldı.

\section{Plak indeksi ve gingival indeks}

Plak indeksi ölçümleri ve dişeti enflamasyon değerleri her bir dişin tüm yüzeylerinden elde edildi ve ortalamaları alınarak dişlere ait PI ve Gi değerleri saptandı. Daha sonra elde edilen veriler toplam diş sayısına bölünerek her bir hasta için ortalama Pi ve Gi değerleri hesaplandı.

\section{Sondlama cep derinliği}

Tüm dişlerde Williams periodontal sond ${ }^{1}$ yardımıyla dişeti kenarı ile sondlanabilir sulkus/cep tabanı arası mesafe milimetrik olarak ölçüldü. Sondlama esnasında tam olmayan ölçümler bir üst değere yuvarlandı. Meziobukkal, bukkal, distobukkal, distolingual, lingual ve meziolingual olmak üzere tüm dişlerin altı noktasından ölçüm yapıldı. Sondlama esnasında sondun, dişin uzun aksına paralel olmasına ve aşırı kuvvet uygulanmamasına dikkat edildi. Daha sonra tüm ölçümlerin aritmetik ortalaması alınarak her bir dişe ve hastaya ait değerler belirlendi. 


\section{Klinik ataşman kaybı}

Tüm dişlerin mine-sement sınırı ile sondlanabilir sulkus/cep tabanı arasındaki mesafe Williams periodontal sond kullanılarak ölçüldü. Ölçümler dişlerin meziobukkal, bukkal, distobukkal, distolingual, lingual ve meziolingual bölgelerinden yapıldı ve değerlerin ortalamaları alınarak her bir hastaya ait KAK düzeyleri belirlendi.

\section{Periodontal teşhis}

Hastaların muayenesinde ve periodontal doku sağlığının teşhisinde klinik periodontal parametreler, bitewing ve panoramik radyograflardan yararlanılarak üçüncü molarlar hariç tüm dişler değerlendirildi. Periodontal olarak sağlıkı kontrol grubu ağız içinde $<2 \mathrm{Gi},<3 \mathrm{~mm} \mathrm{SCD}$ olan ve interproksimal ataşman kaybı bulunmayan bireyler arasından seçildi. Araştırmanın deney grubunu agresif periodontitis teşhisi konulmuş hastalar oluşturdu. Agresif periodontitis teşhisi Amerikan Periodontoloji Akademisi "American Academy of Periodontology"'nin 1999 yılında yayınladığı sınıflandırma esas alınarak yapıldı (Armitage 1999). LAP $(n=50)$ teşhisi için birinci azı dişi veya kesici dişleri içeren en az iki daimi dişte $\geq 4 \mathrm{~mm}$ interproksimal ataşman kaybı varlığına ve bunlardan bir tanesi birinci azı dişi olmak kaydıyla, diğer birinci azı dişleri ve kesici dişlerin dışında ikiden daha fazla dişinde interproksimal kemik kaybı olmamasına dikkat edildi. GAP $(n=30)$ teşhisi için de birinci azı dişleri ve kesici dişler haricinde en az üç daimi dişi içeren generalize ataşman kaybı olması göz önünde bulunduruldu (Armitage 2004).

\section{Dişeti oluğu sıvısı örneklerinin elde edilmesi}

Her bir bireyde alt çenede iki ve üst çenede iki çok köklü (küçük azı/azı) diş olmak üzere SCD en fazla olan toplam dört dişten DOS toplandı. Örneklemeler tüm klinik periodontal ölçümler kaydedildikten 24-48 saat sonra yapıldı ve örnekleme için 10:00 ile 13:00 saatleri arası tercih edildi. DOS örnekleri Kağıt şerit ${ }^{2}$ sulkus içerisine $1 \mathrm{~mm}$ yerleştirilerek "modifiye sulkus içi yöntem" ile bölgede 30 saniye süre beklenmesi sonucunda elde edildi. Kan ve salya bulaşan kağıt şeritler çalışmaya dahil edilmedi. Her bir örnekleme öncesi cihazın iletkenleri alkollü pamuk ile silinerek kurutuldu ve yeni bir kağıt şerit cihaza okutularak "00" değeri elde edildi. Daha sonra örnekleme bölgesinden alınan kağıt şeritteki sıvı miktarı Periotron $8000^{3}$ cihazı ile ölçüldü. Periotron ile belirlenen değerlerler kalibre edilmiş periotron ünitesi tarafından asıl hacim değerleri olan mikrolitreye $(\mu \mathrm{l})$ çevrildi.

\footnotetext{
2 Pro Flow Inc., New York, USA

${ }^{3}$ Periotron 8000, Harco Electronics, Winnipeg, CANADA
}

\section{Periotron cihazının kalibrasyonu}

Periotron cihazı olası buharlaşma miktarını en aza indirmek için örneklemelerin yapıldığı ortamda konumlandırılmış ve cihazın kalibrasyonu üretici firmanın talimatlarına uyularak yapılmışıtır. Kalibrasyon işlemi $1 \mu$ l'lik Hamilton şırıngası ile distile su kullanılarak gerçekleştirilmiştir. Buna göre 0.1, 0.2, 0.3, 0.4, 0.5, 0.6 ve $0.7 \mu \mathrm{l}$ hacmindeki sıvılar ayrı ayrı kağıt şeritlere emdirilmiş ve aygıta okutulmuştur. Bu işlem her bir $\mu \mathrm{l}$ değeri için 3 kere tekrar edilmiş ve ortalamaları alınarak sonuç bir değer elde edilmiştir. Elde edilen bu değer cihazın bilgisayar programına kaydedilmiştir.

\section{İstatiksel analiz}

$S$ ve agresif periodontitis teşhisi konulmuş bireyler arasındaki nümerik verilerin farklıı̆ının değerlendirilmesinde non-parametrik bir test olan Mann-Whitney U testi kullanıldı. S, LAP ve GAP teşhisi konulmuş bireyler arasındaki farklılık Kruskal Wallis testi ile değerlendirilerek gruplar arası anlamlı farklılı̆ın olduğu parametreler Bonferroni düzeltmeli MannWhitney $U$ testi ile karşılaştırıldı. Dişeti oluğu sıvısı hacim $(\mu l)$ değerlerinin klinik periodontal parametreler ile ilişkisini değerlendirmek için Spearman korelasyon analizi kullanıldı. Tüm istatistiksel farklııklar \%95 güven aralı̆ı̆ında ve $p$ değeri $<0.05$ olacak şekilde değerlendirildi.

\section{BULGULAR}

\section{Klinik bulgular}

$\mathrm{Bu}$ araştırma periodontal olarak $\mathrm{S} 80$ ve AP teşhisi konulmuş 80 (50 LAP, $30 \mathrm{GAP}$ ) olmak üzere toplam 160 birey ile tamamlandı. Bireylere ait yaş, ağızda bulunan diş sayıları ve klinik periodontal parametre değerleri Tablo 1 ve Tablo 2'de verildi. 
Tablo 1.

\section{Sağlıklı ve agresif periodontitis teşhisi konulmuş bireylerin klinik ve demografik bilgileri}

\begin{tabular}{|lccc|}
\hline & $\begin{array}{c}\text { Sağlıklı } \\
\text { (n:80) }\end{array}$ & AP (n:80) & p-Value* \\
\hline Yaş & $27.35 \pm 4.25$ & $28.15 \pm 5.26$ & 0.168 \\
\hline $\begin{array}{l}\text { Cinsiyet } \\
\text { (kadın/erkek) }\end{array}$ & $54 / 26$ & $56 / 24$ & 0.733 \\
\hline Diş sayısı & $27.83 \pm 0.44$ & $26.33 \pm 2.37$ & 0.000 \\
\hline Pi & $1.04 \pm 0.66$ & $2.32 \pm 0.38$ & 0.000 \\
\hline Gi & $0.82 \pm 0.15$ & $2.01 \pm 0.37$ & 0.000 \\
\hline SCD (mm) & $1.68 \pm 0.18$ & $3.67 \pm 0.97$ & 0.000 \\
\hline KAK (mm) & 0.00 & $3.07 \pm 1.70$ & 0.000 \\
\hline SCD (\%) & & & \\
\hline $4-5 \mathrm{~mm}$ & 0.00 & $24.52 \pm 11.34$ & 0.000 \\
\hline$\geq 6 \mathrm{~mm}$ & 0.00 & $15.03 \pm 11.75$ & 0.000 \\
\hline KAK (\%) & & & \\
\hline $3-5 \mathrm{~mm}$ & 0.00 & $22.5 \pm 11.42$ & 0.000 \\
\hline$\geq 6 \mathrm{~mm}$ & 0.00 & $20.04 \pm 15.58$ & 0.000 \\
\hline
\end{tabular}

${ }^{*}$ Chi-square testi cinsiyet, Mann Whitney U testi ise diğer parametrelerdeki farklılıların değerlendirilmesinde kullanılmıștır $(p<0.05)$. Değerler ortalama \pm standart sapma olarak verilmiştir.

n: birey sayısI, AP: agresif periodontitis, Pi: plak indeksi, Gi: gingival indeks, SCD: sondlama cep derinliği, KAK: klinik ataşman kaybı.

\section{Dişeti oluğu sıvısı hacim değerleri}

$\mathrm{Bu}$ araştırmaya dahil edilen bireylerden toplam 160 DOS örneği elde edildi. Agresif periodontitis grubunda toplam 12 bireyin DOS hacim değerleri periotron cihazının kalibrasyon değerlerinin dışında kaldığı için hacim hesaplamaları yapılamadı.

Dişeti oluğu sıvısı hacminin ( $\mu$ l) gruplara göre dağılımı Tablo 3'de verildi. Yapılan değerlendirme sonucunda $S$ ve AP gruplarının DOS hacmi kıyaslandığında fark anlamlıydı $(p<0.05$, Şekil $1 A)$. Ancak LAP ve GAP grupları arasındaki fark önemli bulunmadı $(p>0.05$, Şekil 1B).
Tablo 2.

Sağlıklı, lokalize agresif periodontitis ve generalize agresif periodontitis teşhisi konulmuş bireylerin klinik ve demografik bilgileri

\begin{tabular}{|lcccc}
\hline & $\begin{array}{c}\text { Sağlıklı } \\
\text { (n:80) }\end{array}$ & LAP (n:30) & GAP (50) & p-Value* \\
\hline Yaş & $27.35 \pm 4.25$ & $27.24 \pm 4.66$ & $29.67 \pm 5.90^{\mathrm{ab}}$ & 0,03 \\
\hline $\begin{array}{l}\text { Cinsiyet } \\
\text { (kadın/erkek) }\end{array}$ & $54 / 26$ & $34 / 16$ & $22 / 8$ & 0,833 \\
\hline Diş sayısı & $27.83 \pm 0.44$ & $26.86 \pm 1.37^{\mathrm{a}}$ & $25.43 \pm 3.29^{\mathrm{ab}}$ & 0.000 \\
\hline Pi & $1.04 \pm 0.66$ & $2.09 \pm 022^{\mathrm{a}}$ & $2.69 \pm 027^{\mathrm{ab}}$ & 0.000 \\
\hline Gi & $0.82 \pm 0.15$ & $1.80 \pm 0.28^{\mathrm{a}}$ & $2.35 \pm 0.22^{\mathrm{ab}}$ & 0.000 \\
\hline SCD (mm) & $1.68 \pm 0.18$ & $3.09 \pm 0.47^{\mathrm{a}}$ & $4.63 \pm 0.79^{\mathrm{ab}}$ & 0.000 \\
\hline KAK (mm) & 0.00 & $1.94 \pm 0.78^{\mathrm{a}}$ & $4.84 \pm 1.20^{\mathrm{ab}}$ & 0.000 \\
\hline SCD (\%) & 0.00 & & & 0.000 \\
\hline $4-5 \mathrm{~mm}$ & 0.00 & $19.77 \pm 8.08^{\mathrm{a}}$ & $32.45 \pm 11.67^{\mathrm{ab}}$ & 0.000 \\
\hline 26 mm & 0.00 & $8.63 \pm 5.73^{\mathrm{a}}$ & $25.69 \pm 11.50^{\mathrm{ab}}$ & 0.000 \\
\hline KAK (\%) & & & & \\
\hline 3-5 mm & 0.00 & $17.81 \pm 8.21^{\mathrm{a}}$ & $30.36 \pm 11.83^{\mathrm{ab}}$ & 0.000 \\
\hline$\geq 6 \mathrm{~mm}$ & 0.00 & $11.15 \pm 5.76^{\mathrm{a}}$ & $34.86 \pm 15.57^{\mathrm{ab}}$ & 0.000 \\
\hline$\times$ Chi-squre & & & & \\
\hline
\end{tabular}

*Chi-square testi cinsiyet, Kruskal Wallis testi-Bonferroni düzeltmesi ise diğer parametrelerdeki farklılıların değerlendirilmesinde kullanılmıştır $(p<0.05)$. Değerler ortalama \pm standart sapma olarak verilmiştir.

a: Sağlıklı kontrollere göre farklılık, b: LAP'a göre farklılı n: birey sayISI, LAP: lokalize agresif periodontitis, GAP: generalize agresif periodontitis Pi: plak indeksi, Gi: gingival indeks, SCD: sondlama cep derinliği, KAK: klinik ataşman kaybı.
A
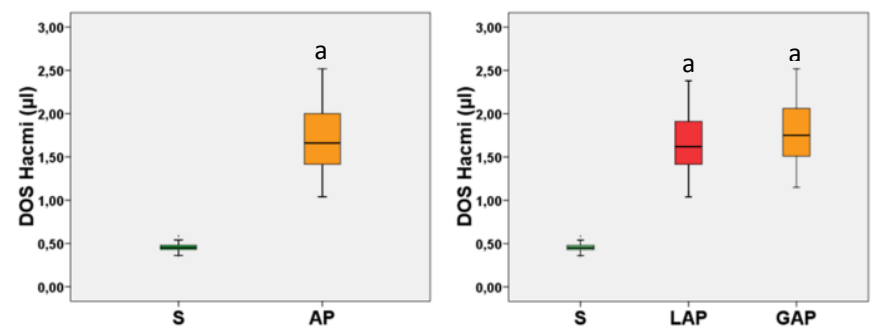

Şekil 1.

DOS hacminin $(\mu \mathrm{l})$ gruplara göre dağılımı

Sağlıklı (S), agresif periodontitis (AP), lokalize agresif periodontitis (LAP) ve generalize agresif periodontitis (GAP) (a:Sağlıklı gruba göre farklılık) 
Tablo 3.

Sağlıklı, lokalize agresif periodontitis ve generalize agresif periodontitis teşhisi konulmuş bireylerde DOS hacmi $(\mu \mathrm{l})$

\begin{tabular}{|c|c|c|c|c|c|c|}
\hline & Sağlıklı & $\begin{array}{c}\text { Lokalize } \\
\text { Agresif } \\
\text { Periodontitis }\end{array}$ & $\begin{array}{c}\text { Generalize } \\
\text { Agresif } \\
\text { Periodontitis }\end{array}$ & İstatistik & Sd & $\mathbf{P}$ \\
\hline $\operatorname{DOS}(\mu \mathrm{l})$ & & & & \multirow{5}{*}{$\begin{array}{l}K-W= \\
96.51\end{array}$} & \multirow{5}{*}{2} & \multirow{5}{*}{0.00} \\
\hline$n$ & 80 & 43 & 25 & & & \\
\hline Ort \pm Ss & $0.45 \pm 0.05$ & $1.64 \pm 0.32^{\mathrm{a}}$ & $1.77 \pm 0.37^{\mathrm{a}}$ & & & \\
\hline $\begin{array}{l}\text { Min- } \\
\text { Maks }\end{array}$ & $0.34-0.59$ & $1.04-2.38$ & $1.15-2.52$ & & & \\
\hline Ortanca & 0.45 & 1.62 & 1.75 & & & \\
\hline
\end{tabular}

Periodontal olarak S, LAP ve GAP teşhisi konulmuş bireylerde örnekleme bölgesinin klinik periodontal parametreleri Şekil 2'de gösterildi. Tüm klinik parametrelerin gruplar arasında farklı olduğu gözlendi $(p<0.05)$.
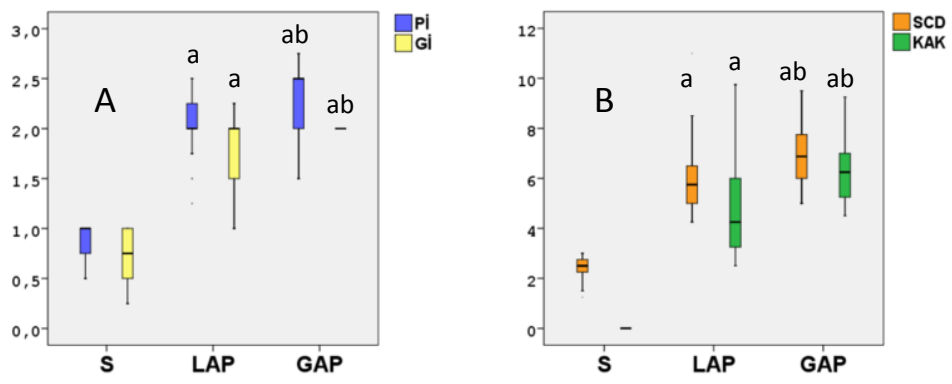

Şekil 2.

Sağlıklı (S), lokalize agresif periodontitis (LAP) ve generalize agresif periodontitis (GAP) teşhisi konulmuş bireylerin örnekleme bölgesinin A: Plak indeksi (PI) ve gingival indeks (GI) B: Sondlama cep derinliği (SCD) ve klinik ataşman kaybı (KAK) değerleri (a: Sağlıklı gruba göre farklılık; b: lokalize agresif periodontitise göre farkl1lık)

Tablo 4.

Agresif periodontitis teşhisi konulmuş bireylerde örnekleme bölgesinin klinik periodontal parametreleri ile dişeti oluğu sıvısı hacim değerleri arasındaki Spearman korelasyonu $(p<0.05)$.

\begin{tabular}{|lcccc|}
\hline & \multicolumn{5}{c}{$\begin{array}{c}\text { DOS }(\mu \mathrm{l}) \\
\mathbf{n = 8 4}\end{array}$} & & \\
\hline & Pi & Gi & SCD $(\mathbf{m m})$ & KAK(mm) \\
\hline Korelasyon & 0.126 & 0.054 & 0.252 & 0.371 \\
\hline p & 0.307 & 0.663 & $\mathbf{0 . 0 3 8}$ & $\mathbf{0 . 0 0 2}$ \\
\hline
\end{tabular}

n: birey sayısı, Pi: plak indeksi, Gi: gingival indeks, SCD: sondlama cep derinliği, KAK: klinik ataşman kaybı
Agresif periodontitis teşhisi konulmuş bireylerde DOS hacmi ile klinik periodontal parametreler arasındaki korelasyon değerleri Tablo 4'de gösterildi.

\section{TARTIŞMA}

Hormonal değişimler, yaş, sigara gibi faktörlerin periodontal doku sağlığına olası etkileri nedeniyle, bu araştırma yaş ve cinsiyet olarak eşleştirilmiş 107 sağlıklı ve 108 agresif periodontitis teşhisi konulmuş sigara kullanmayan bireyler üzerinde yürütüldü. Böylece çevresel ve kazanılmış faktörlerin elimine edilerek çalışma gruplarının biraz daha dengeli ve homojen olmasına dikkat edildi. Periodontal doku yıkımının bir sonucu olarak AP hastalarının $S$ grubuna göre daha az sayıda dişe sahip olduğu gözlendi. Agresif periodontitis hastaları daha sonra LAP ve GAP olmak üzere alt gruplara ayrıldığında (Armitage 1999), cinsiyet açısından fark olmadığı ancak GAP hastalarının ilerlemiş periodontal hastalıkla paralel olarak daha az sayıda dişe sahip olduğu ve yaş ortalamasının LAP ve sağlıklı gruba göre daha fazla olduğu gözlendi.

Sigaranın mikrobiyal kompozisyonda değişime (Haffajee ve Socransky 2001) neden olduğu, aynı zamanda damarsal yapı, nötrofil/monosit aktiviteleri, adezyon molekül ekspresyonu ve antikor üretimini içeren konak cevabına olan etkileri ile periodontal hastalık için bir risk faktörü olduğu bilinmektedir (Bergstrom ve Eliasson 1987,Sopori 2002). Bu nedenle sigarayı bırakmış ve/veya sigara içen bireyler bu çalışma kapsamına alınmadı.

Bu araştırmada periodontal hastalık şiddeti ile artış gösteren klinik periodontal parametrelerin LAP ve GAP gruplarında da farklılık gösterdiği tespit edildi. Özellikle KAK ve $S C D \geq 6 \mathrm{~mm}$ olan alanların yüzdesi sırasıyla LAP grubunda \%11.15 ve \%8.63 iken GAP grubunda bu oran \%34.86 ve \%25.69 olarak saptandı. Bu veriler en fazla doku yıkımının, hastalığın tabiatına paralel olarak, GAP grubunda olduğunu göstermektedir.

\section{Dişeti oluğu Sıvısı hacmi}

Dişeti oluğu sıvısı fizyolojik bir sıvıdır ve birleşim epitelinin altındaki kan damarları ağından köken alan enflamatuvar eksuda olarak tanımlanır (Lamster ve Novak 1992). 
Ancak, DOS çok az miktarda elde edilebilmekte ve geniş bir hacimsel aralıkta değişim göstermektedir (Lamster ve ark 1991, Smith ve Geegan 1991, Griffiths ve ark 1992, Page 1992, Ozkavaf ve ark 2000). Bu araştırmada DOS'un daha kısa zamanda ve kolay olarak toplanması amaciyla (Gupta ve ark 2013) $2 \mathrm{mmx} 7 \mathrm{~mm}$ sabit boyuttaki kağıt şeritler kullanıldı. Bu yöntem kağıt şeritlerin ağırıklarının belirlenmesi veya elektriksel kapasitelerinin Periotron cihazı ile ölçülmesi sonucu hacimlerinin hesaplanabilmesine olanak vermektedir (Gustafsson 1996). Ancak, bu uygulamanın oda sıcaklığının olası muhtemel etkisi, nem miktarı, örneklerin buharlaşması, kağıt şeritlerin cihazda konumlandırılma şekli, sıvının cihazda bırakmış olabileceği kalıntı miktarı, cihaz kalibrasyonunun devamlılığı ve güvenilirliği (Suppipat ve Suppipat 1977, Garnick ve ark 1979, Griffiths 2003, Tozum ve ark 2004, Gupta ve ark 2013) ve $0.7 \mu l$ 'den daha fazla hacimlerin ölçülememesi gibi bazı limitasyonları olmasına karşın, literatürde birçok çalışmada DOS toplanması amacıyla yaygın olarak kullanılmaktadır (Tozum ve ark 2004, Guncu ve ark 2006, Ustun ve Alptekin 2007, Baltacioglu ve ark 2014).

Günümüze kadar yapılan birçok çalışma sigara içen bireylerin DOS hacminin ve akış hızının sigara içmeyen bireylere göre daha az olduğunu göstermiştir (Holmes 1990, Rosa ve ark 2000, Apatzidou ve ark 2005, Gomes ve ark 2009, Mokeem ve ark 2014). Sigara içilmesinin hemen sonrasında kan akımının artış gösterdiği ve dişetindeki irritasyona bağlı olarak DOS akış hızının arttığı (McLaughlin ve ark 1993), sigara kullanımının devam etmesi durumunda ise bileşenlerindeki maddelerin vazokonstrüksiyon etkisine ve mikrosirkülasyondaki bozulmaya bağı olarak azaldığı tespit edilmiştir. Bu çalışmalardan farklı olarak Ustun ve Alptekin (2007) yapmış oldukları bir araştırmada sigara içen bireylerin DOS hacminin içmeyen bireylere göre daha fazla olduğunu gözlemlemişlerdir. Ancak sigara kullanımını bırakan bireylerden erken dönemde alınan DOS hacminin ve akış hızının artış gösterdiğinin tespit edilmesi (Morozumi ve ark 2004), sigaranın DOS hacmi üzerine olan negatif etkisini destekler niteliktedir. Bu bilgiler ışığında periodontal hastalık için risk faktörü olduğu bilenen sigaranın DOS hacmi üzerine de olası etkileri nedeniyle bu araştırmaya sigara içen bireyler dahil edilmemiştir.

Dişeti oluğu sıvısı hacminin gün içinde farklı zamanlarda değişiklik gösteren (Bergmann ve Deinzer 2008) "sirkadyen ritim" içerisinde olduğu saptanmıştır (Bulkacz ve Carranza 2009). Ancak, Gunday ve ark. (2014) sirkadyen periyodun DOS hacmini etkilemediğini rapor etmişlerdir. Bu araştırmada tüm bireylerden DOS örneklemelerinin daha standart şartlar altında toplanması amacıyla günün 1000 ile 1300 saatleri arası tercih edilmiştir.

Literatürde DOS toplanmasında ilk örneklerin durağan "static" (Lamster ve ark 1989) veya "resting" (Atici ve ark
1998) hacim olarak ele alındığı ve ikinci örneklerin de sıvı akışı "flow" (Ozkavaf ve ark 2000) olarak değerlendirilebileceği ileri sürülmüştür. Günümüze kadar yapılan çalışmalar DOS hacmi açısından değerlendirildiğinde, çalışmaların \%85'inde ilk örnekleme sonuçları, sulkus/cep içerisine olan SIVı akış oranı "flow rate/flow" olarak rapor edilmiştir. Aslında klinik pratikte tek seferde yapılan örneklemelerin bu şekilde değerlendirilmesi, daha önceki çalışmalarda "static" DOS örneği (Lamster ve ark 1989) veya "resting " hacmin sifır olması durumunda doğru olmaktadır. Ancak, periodontal sağlıkta bile durağan miktar sıfır olmamakta, periodontal cep derinliğine paralel olarak artmaktadır. Bu çalışmada da DOS analizinde yapılan ilk örneklemeler kullanılmış ve DOS miktarının aslında "flow" ve "resting " hacmin toplamı olduğu bilgisi (Goodson 2003) esas alınmıştır.

Bu çalışmada DOS örnekleri kağıt şeritler sulkus içine $1 \mathrm{~mm}$ yerleştirilerek "modifiye sulkus içi yöntem" ile toplandı ve gingival sulkus/periodontal cepte doku hasarı oluşturmamasına dikkat edildi. Dişeti oluğu sıvısı her bir örnek için 30 sn süre ile sabit zamanda elde edildi (Lamster ve ark 1988, Lamster 1997, Lamster ve Ahlo 2007). Bu araştırmada $80 \mathrm{~S}$ ve $80 \mathrm{AP}$ olmak üzere 160 bireyden DOS toplandı, ancak AP grubunda 12 örneğin DOS hacmi Periotron cihazının kalibrasyon değerleri dışında kalması nedeniyle ölçümü yapılamadı. Toplanan DOS hacminin, AP grubunda $S$ kontrollere göre daha yüksek olduğu saptandı, ancak LAP ve GAP arasında kıyaslandığında gruplar arasında farklıık tespit edilmedi. Elde edilen bu sonuç sağlıklı periodontal dokularda DOS hacminin düşük düzeylerde olduğu (Ozkavaf ve ark 2000,Ay ve ark 2012) görüşünü desteklemektedir.

Literatürde DOS hacim değişiklikleri inceleyen çalışmalarda, DOS hacminin artan enflamasyon derecesi ile paralel olarak artış gösterdiği tespit edilmiştir (Bhardwaj ve Prabhuji 2013). Bu araştırmada ise agresif periodontitis hastalarında DOS hacim değerlerinin plak miktarı ve enflamasyon derecesi ile ilişkili olmadığı ancak periodontal kayıp miktarını gösteren SCD ve KAK ile pozitif yönde korelasyon gösterdiği tespit edilmiştir. Bu durum agresif periodontitis hastalarında periodontal yıkım miktarının enflamasyon ve eklenti miktarından bağımsız olduğu görüşünü destekler niteliktedir (Armitage 2004).

\section{Teşekkür}

İstatistiksel analizlerdeki değerli yardımları için Balıkesir Üniversitesi Tıp Fakültesi Halk Sağlı̆̆ı Anabilim Dalı öğretim üyesi Prof. Dr.Said BODUR'a teşekkür ederiz. 


\section{KAYNAKLAR}

Albandar JM, Tinoco EM, 2002. Global epidemiology of periodontal diseases in children and young persons. Periodontol 2000, 29, 153-176.

Anil S, Preethanath RS, Alasqah M, Mokeem SA, Anand PS, 2013. Increased levels of serum and gingival crevicular fluid monocyte chemoattractant protein-1 in smokers with periodontitis. J Periodontol, 84, e23-28.

Apatzidou DA, Riggio MP, Kinane DF, 2005. Impact of smoking on the clinical, microbiological and immunological parameters of adult patients with periodontitis. J Clin Periodontol, 32, 973-983.

Armitage GC, 1999. Development of a classification system for periodontal diseases and conditions. Ann Periodontol, 4, 1-6.

Armitage GC, 2004. Analysis of gingival crevice fluid and risk of progression of periodontitis. Periodontol 2000, 34, 109-119.

Armitage GC, 2004. Periodontal diagnoses and classification of periodontal diseases. Periodontol 2000, 34, 9-21.

Atici K, Yamalik N, Eratalay K, Etikan I, 1998. Analysis of gingival crevicular fluid intracytoplasmic enzyme activity in patients with adult periodontitis and rapidly progressive periodontitis. A longitudinal study model with periodontal treatment. J Periodontol, 69, 11551163.

Ay ZY, Yilmaz G, Ozdem M, Kocak H, Sutcu R, Uskun $E$ ve ark, 2012. The gingival crevicular fluid levels of interleukin-11 and interleukin-17 in patients with aggressive periodontitis. J Periodontol, 83, 14251431.

Baltacioglu E, Kehribar MA, Yuva P, Alver A, Atagun OS, Karabulut E ve ark, 2014. Total oxidant status and bone resorption biomarkers in serum and gingival crevicular fluid of patients with periodontitis. J Periodontol, 85, 317-326.

Becerik S, Ozturk VO, Atmaca H, Atilla G, Emingil G, 2012. Gingival crevicular fluid and plasma acute-phase cytokine levels in different periodontal diseases. J Periodontol, 83, 1304-1313.

Bergmann A, Deinzer R, 2008. Daytime variations of interleukin-1beta in gingival crevicular fluid. Eur $\mathrm{J}$ Oral Sci, 116, 18-22.

Bergstrom J, Eliasson S, 1987. Cigarette smoking and alveolar bone height in subjects with a high standard of oral hygiene. J Clin Periodontol, 14, 466-469.
Bhardwaj S, Prabhuji ML, 2013. Comparative volumetric and clinical evaluation of peri-implant sulcular fluid and gingival crevicular fluid. J Periodontal Implant Sci, 43, 233-242.

Bulkacz J, Carranza FA 2009, Defence Mechanisms of the Gingiva, In: Carranza's clinical periodontology, M. G. Newman, H. H. Takei, P. R. Klokkevold and F. A. Carranza. China, W.B Saunders Company. 344-354.

Garnick JJ, Pearson R, Harrell D, 1979. The evaluation of the periotron. J Periodontol, 50, 424426.

Gomes SC, Piccinin FB, Oppermann RV, Susin C, Marcantonio RA, 2009. The effect of smoking on gingival crevicular fluid volume during the treatment of gingivitis. Acta Odontol Latinoam, 22, 201-206.

Goodson JM, 2003. Gingival crevice fluid flow. Periodontol 2000, 31, 43-54.

Griffiths GS, 2003. Formation, collection and significance of gingival crevice fluid. Periodontol 2000, 31, 32-42.

Griffiths GS, Sterne JA, Wilton JM, Eaton KA, Johnson NW, 1992. Associations between volume and flow rate of gingival crevicular fluid and clinical assessments of gingival inflammation in a population of British male adolescents. J Clin Periodontol, 19, 464-470.

Guentsch A, Kramesberger M, Sroka A, Pfister W, Potempa J, Eick S, 2011. Comparison of gingival crevicular fluid sampling methods in patients with severe chronic periodontitis. J Periodontol, 82, 1051-1060.

Guncu GN, Caglayan F, Dincel A, Bozkurt A, Saygi S, Karabulut E, 2006. Plasma and gingival crevicular fluid phenytoin concentrations as risk factors for gingival overgrowth. J Periodontol, 77, 2005-2010.

Gunday S, Topcu AO, Ercan E, Yamalik N, 2014. Analysis of daytime variations in gingival crevicular fluid: a circadian periodicity? J Periodontol, 85, e47-56.

Gupta M, Chaturvedi R, Jain A, 2013. Role of monocyte chemoattractant protein-1 (MCP-1) as an immune-diagnostic biomarker in the pathogenesis of chronic periodontal disease. Cytokine, 61, 892-897. 
Gustafsson A, 1996. Methodological considerations in GCF sampling with paper strips: poor recovery of uncomplexed elastase. J Clin Periodontol, 23, 432436.

Haffajee AD, Socransky SS, 2001. Relationship of cigarette smoking to the subgingival microbiota. $\mathrm{J}$ Clin Periodontol, 28, 377-388.

Hernandez M, Gamonal J, Tervahartiala T, Mantyla P, Rivera O, Dezerega A ve ark, 2010. Associations between matrix metalloproteinase- 8 and -14 and myeloperoxidase in gingival crevicular fluid from subjects with progressive chronic periodontitis: a longitudinal study. J Periodontol, 81, 1644-1652.

Ho W, Eubank T, Leblebicioglu B, Marsh C, Walters J, 2010. Azithromycin decreases crevicular fluid volume and mediator content. J Dent Res, 89, 831-835.

Holmes LG, 1990. Effects of smoking and/or vitamin $\mathrm{C}$ on crevicular fluid flow in clinically healthy gingiva. Quintessence Int, 21, 191-5.

Johnson NW, 1991. Crevicular fluid-based diagnostic tests. Curr Opin Dent, 1, 52-65.

Kleinberg I, Golub LM, 1985. Gingival crevicular fluid and its use in diagnosis of disease. Int $\mathrm{J}$ Dermatol, 24, 37-40.

Kurtis B, Tuter G, Serdar M, Akdemir P, Uygur C, Firatli $E$ ve ark, 2005. Gingival crevicular fluid levels of monocyte chemoattractant protein-1 and tumor necrosis factor-alpha in patients with chronic and aggressive periodontitis. J Periodontol, 76, 18491855.

Lamster IB, 1997. Evaluation of components of gingival crevicular fluid as diagnostic tests. Ann Periodontol, 2, 123-137.

Lamster IB, Ahlo JK, 2007. Analysis of gingival crevicular fluid as applied to the diagnosis of oral and systemic diseases. Ann N Y Acad Sci, 1098, 216-229.

Lamster IB, Harper DS, Goldstein S, Celenti RS, Oshrain RL, 1989. The effect of sequential sampling on crevicular fluid volume and enzyme activity. J Clin Periodontol, 16, 252-258.

Lamster IB, Novak MJ, 1992. Host mediators in gingival crevicular fluid: implications for the pathogenesis of periodontal disease. Crit Rev Oral Biol Med, 3, 31-60.
Lamster IB, Oshrain RL, Celenti R, Levine K, Fine JB, 1991. Correlation analysis for clinical and gingival crevicular fluid parameters at anatomically related gingival sites. J Clin Periodontol, 18, 272-277.

Lamster IB, Oshrain RL, Fiorello LA, Celenti RS, Gordon JM, 1988. A comparison of 4 methods of data presentation for lysosomal enzyme activity in gingival crevicular fluid. J Clin Periodontol, 15, 347352.

Leppilahti JM, Kallio MA, Tervahartiala T, Sorsa T, Mantyla P, 2014. Gingival crevicular fluid matrix metalloproteinase-8 levels predict treatment outcome among smokers with chronic periodontitis. J Periodontol, 85, 250-260.

Loe H, Holm-Pedersen P, 1965. Absence and Presence of Fluid from Normal and Inflamed Gingivae. Periodontics, 149, 171-177.

Loe H, Silness J, 1963. Periodontal Disease in Pregnancy. I. Prevalence and Severity. Acta Odontol Scand, 21, 533-551.

Mann WV, 1963. The correlation of gingivitis pocket depth and exsudate from the gingival crevice. Journal of Periodontology, 34, 79-87.

Markou E, Eleana B, Lazaros T, Antonios K, 2009. The influence of sex steroid hormones on gingiva of women. Open Dent J, 3, 114-119.

McLaughlin WS, Lovat FM, Macgregor ID, Kelly PJ, 1993. The immediate effects of smoking on gingival fluid flow. J Clin Periodontol, 20, 448-451.

Mokeem SA, Vellappally S, Preethanath RS, Hashem MI, Al-Kheraif AA, Anil S, 2014. Influence of smoking on clinical parameters and gingival crevicular fluid volume in patients with chronic periodontitis. Oral Health Dent Manag, 13, 469-473.

Morozumi T, Kubota T, Sato T, Okuda K, Yoshie H, 2004. Smoking cessation increases gingival blood flow and gingival crevicular fluid. J Clin Periodontol, 31, 267-272.

Nowicki D, Vogel RI, Melcer S, Deasy MJ, 1981. The gingival bleeding time index. J Periodontol, 52, 260262.

Ozkavaf A, Aras H, Huri CB, Mottaghian-Dini F, Tozum TF, Etikan I ve ark, 2000. Relationship between the quantity of gingival crevicular fluid and clinical periodontal status. J Oral Sci, 42, 231-238. 
Page RC, 1992. Host response tests for diagnosing periodontal diseases. J Periodontol, 63, 356-366.

Persson GR, DeRouen TA, Page RC, 1990. Relationship between gingival crevicular fluid levels of aspartate aminotransferase and active tissue destruction in treated chronic periodontitis patients. J Periodontal Res, 25, 81-87.

Pradeep AR, Daisy H, Hadge P, 2009. Gingival crevicular fluid levels of monocyte chemoattractant protein-1 in periodontal health and disease. Arch Oral Biol, 54, 503-509.

Rosa GM, Lucas GQ, Lucas ON, 2000. Study of the crevicular fluid flow rate in smokers. Acta Odontol Latinoam, 13, 51-60.

Sakai A, Ohshima M, Sugano N, Otsuka K, Ito K, 2006. Profiling the cytokines in gingival crevicular fluid using a cytokine antibody array. J Periodontol, 77, 856-864.

Silness J, Loe H, 1964. Periodontal Disease in Pregnancy. li. Correlation between Oral Hygiene and Periodontal Condtion. Acta Odontol Scand, 22, 121-135.

Smith QT, Geegan SJ, 1991. Repeated measurement of crevicular fluid parameters at different sites. J Clin Periodontol, 18, 171-176.

Sopori M, 2002. Effects of cigarette smoke on the immune system. Nat Rev Immunol, 2, 372-377.

Stoller NH, Karras DC, Johnson LR, 1990. Reliability of crevicular fluid measurements taken in the presence of supragingival plaque. J Periodontol, 61, 670-673.

Suppipat N, Suppipat N, 1977. Evaluation of an electronic device for gingival fluid quantitation. J Periodontol, 48, 388394.

Tozum TF, Hatipoglu H, Yamalik N, Gursel M, Alptekin NO, Ataoglu T ve ark, 2004. Critical steps in electronic volume quantification of gingival crevicular fluid: the potential impact of evaporation, fluid retention, local conditions and repeated measurements. J Periodontal Res, 39, 344-357.

Tozum TF, Yildirim A, Caglayan F, Dincel A, Bozkurt A, 2004. Serum and gingival crevicular fluid levels of ciprofloxacin in patients with periodontitis. J Am Dent Assoc, 135, 1728-1732.

Ustun K, Alptekin NO, 2007. The effect of tobacco smoking on gingival crevicular fluid volume. Eur J Dent, 1, 236-239.

\section{Yazışma Adresi:}

Şadiye COŞKUNER

Abant İzzet Baysal Üniversitesi

Diş Hekimliği Fakültesi

Periodontoloji AD

Bolu, Türkiye

E-Mail: coskunersadiye@gmail.com 